\title{
Histopathological evaluation of cerebral lesions
}

\author{
Minesh B. Gandhi ${ }^{1}$, Harshid L. Patel ${ }^{2, *}$, Aakash Shah ${ }^{3}$ \\ ${ }^{1,2}$ Associate Professor, ${ }^{3}$ Consultant Pathologist, Dept. of Pathology, ${ }^{1}$ Smt. N.H.L. Municipal Medical College, \\ Ahmedabad, Gujarat, ${ }^{2}$ GMERS Medical College, Gandhinagar, Gujarat, India
}

*Corresponding Author:

Email: harshidpatel11111@gmail.com

\begin{abstract}
Introduction: A cerebral lesion refers to any type of abnormal tissue found in the brain, particularly in the cerebral cortex. The cerebrum is responsible for allowing voluntary movements within the human body. Cerebral tumors arise from tissue throughout the brain. Neuroglial cells mainly consist of astrocytes, oligodendrocytes and ependymal cells. These cells provide shelter and maintenance for neurons. About half of the primary CNS tumors derive from glial cells.

Aims and Objectives: To study the lesions of cerebrum with age and sex incidence and to find the incidence between neoplastic and non-neoplastic lesions and correlation with radiological appearance and histopathological findings of the lesions.

Materials and Methods: A present study including of 150 cases of cerebral lesions. All surgical biopsies were taken at department of Neurosurgery and then send for the histopathology examination in department of Pathology of Smt. N.H.L. Municipal Medical College attached with Sheth V.S. General Hospital, Ahmedabad, Gujarat from July 2011 to June 2013.

Results: Out of these total 150 biopsies, 100 were diagnosed as neoplastic lesions and 50 were diagnosed as nonneoplastic lesions. Among the neoplastic lesions, majority cases were of Gliomas (82\%). Among the nonneoplastic lesions, majority cases were of infectious origin (60\%). Out of total 82 cases of gliomas, 64 were of astrocytic Gliomas (78\%). The peak age incidence for patients with neoplastic lesions was the 4th and 5th decade while that for benign lesions was 1st and 3rd decade. The male to female ratio was 2.7:1.

Summary and Conclusion: Among the 100 neoplastic lesions most common was Gliomas. Among the glioma, most common was the Astrocytoma (78\%) which was followed by the oligodendroglioma (11\%) and then Ependymoma (6\%). Overall male: female ratio was 2.7:1 in the patient with Glial tumors. Out of 50 non neoplastic cerebral lesions, $30(60 \%)$ were of infectious origin.
\end{abstract}

Keywords: Astrocytoma, Cerebral lesions, Glioma, Histopathology examination.

Received: $11^{\text {th }}$ July, 2017

\section{Introduction}

The task of evaluating a neuropathological specimen often seems daunting, given the enormity and the complex nature of this organ system and the ever enlarging list of the diseases. However, when a methodical approach is applied using clinical and radiologic, as well as histological information, the chances of error can be significantly reduced. ${ }^{1}$

A cerebral lesion refers to any type of abnormal tissue found on the brain, particularly the area of the brain known as the cerebrum. The cerebrum constitutes the largest portion of the brain and is responsible for allowing voluntary movements within the human body. ${ }^{2}$ The lesions or damage can occur due to some sort of injury, but the development of lesions can also take place during natural disease progression, immune system disorders and exposure to certain organisms seeded by hematogenous route have also been reported to cause lesions in the cerebrum. Cerebral tumors arise from tissue throughout the brain and can be associated with exposure to pollutants, random mutations, and other causes. As tumors grow and spread, they can put pressure on healthy brain cells and potentially cause cell death.

Neuroglial cells comprise astrocytes, oligodendrocytes and ependymal cells. All central nervous system (CNS) cells derive from the neuroectoderm or the neural plate during the embryogenesis. ${ }^{3}$

About $50 \%$ of the primary brain tumors derive from glial cells. Gliomas, in perticular those of astrocytic origin, are the most common of primary brain tumours and account for more than $40 \%$ of all CNS neoplasms. ${ }^{[4]}$ Different types of glial cell tumors vary in their location within the CNS, in age and gender distribution, growth potential, extent of invasiveness, morphological features, tendancy for progression, and clinical course. The grading of gliomas follows the classification by WHO. ${ }^{5} \mathrm{~A}$ grading system is based on the presence of the following criteria: increased cellular density, 
nuclear atypias, mitosis, vascular proliferation and necrosis. The main histological subtype of grade I gliomas are pilocytic astrocytomas, which are benign. Diffuse astrocytomas, oligodendrogliomas and oligoastrocytomas are low-grade (II) or high-grade (III and IV) tumors. Glioblastomas correspond to grade IV astrocytomas. ${ }^{6}$ The gene for malignant astrocytic tumors are located on chromosome 10. Loss of its heterozygosity is main genetic abnormality found in these tumors. The tumor suppressor gene PTEN (MMAC1) on chromosome 10q23 is mutated in approximately $30 \%$ of glioblastomas (WHO Grade IV). ${ }^{7}$

Benign Cerebral tumors may have the potential to become life-threatening. So malignant potential of Cerebral tumors is of two patterns, anatomic and biologic. The former includes deeply seated lesions that could not be reached by the surgeon, and so may progress until become fatal, while the latter includes aggressive tumors that grow rapidly with resulting neuropil invasion and destruction.

So as to summarise Cerebral lesions which are evaluated histologically mainly divided in two broad categories that are Neoplastic and Nonneoplastic. ${ }^{8}$ Histopathological evaluation of cerebral lesion becomes very useful for the further management of the particular lesion.

\section{Aims and Objectives}

1. To study the spectrum of lesions of the cerebrum by histopathological examination,

2. To find the age and sex incidence of these lesions,
3. To find the incidence between neoplastic and non neoplastic lesions of cerebrum,

4. To correlate radiological appearance of lesions of the cerebrum with histopathological findings of the lesions.

\section{Methods and Materials}

A present study including of 150 cases of central nervous system lesions. All these 150 cerebral biopsies were taken at neurosurgery department of Smt. N.H.L. Municipal Medical College, Ahmedabad from July 2011 to June 2013. All relevant clinical details were obtained from patients or his relatives. Each received surgical specimen in Histopathology Section were examined grossly for its size, shape, weight, consistency and appearance. Tissue cut surface was also examined for the presence of hemorrhage, necrosis and cystic spaces etc. All these specimens were preserved in $10 \%$ neutral buffered formalin for fixation for 24 hours.

For histopathological evaluation, numbers of sections were taken from different representative sites according to the size of specimen. While in case of small biopsy specimen the whole specimen was processed.

These representative sections were subjected for processing on automatic tissue processor. After processing the section were embedded in paraffin, cut with microtome at 5 micron thickness and stained with Hematoxylin and Eosin stain. Special staining procedure like Periodic Acid Schiff (PAS), Reticulin and Zeil Nelson (ZN) stain were also done as and when required.

\section{Results}

Table 1: Histopathological diagnosis of cerebral biopsies

\begin{tabular}{|c|c|c|c|c|}
\hline \multicolumn{4}{|c|}{ Histopathological diagnosis } & No of cases \\
\hline \multirow{8}{*}{ Neoplastic lesions } & \multicolumn{3}{|l|}{ Gliomas } & 82 \\
\hline & \multicolumn{3}{|c|}{$\begin{array}{l}\text { Neuronal and glioneuronal tumors, } \\
\text { hamartomas, and related lesions }\end{array}$} & 2 \\
\hline & \multicolumn{3}{|c|}{ Embryonal neuroepithelial tumors } & 0 \\
\hline & \multicolumn{3}{|c|}{ Lymphoma and Leukemia } & 1 \\
\hline & \multicolumn{3}{|c|}{ Germ Cell Tumors } & 0 \\
\hline & \multicolumn{3}{|c|}{ Secondary tumors (Metastatic) } & 13 \\
\hline & \multicolumn{3}{|c|}{$\begin{array}{l}\text { Undifferentiated malignant round cell } \\
\text { tumor }\end{array}$} & 2 \\
\hline & \multicolumn{3}{|l|}{ TOTAL } & 100 \\
\hline \multirow{6}{*}{$\begin{array}{l}\text { Non } \\
\text { lesions }\end{array}$} & \multirow[t]{2}{*}{ Infectious } & Tuberculosis & 6 & \multirow[t]{2}{*}{30} \\
\hline & & Other & 24 & \\
\hline & \multirow[t]{2}{*}{ Cyst } & Hydatid cyst & 2 & \multirow[t]{2}{*}{11} \\
\hline & & Others & 9 & \\
\hline & \multicolumn{3}{|c|}{ Demyelinating disease } & 1 \\
\hline & \multicolumn{3}{|c|}{ Reactive gliosis } & 6 \\
\hline
\end{tabular}




\begin{tabular}{|l|l|c|}
\hline & AV malformation & 2 \\
\cline { 2 - 3 } & TOTAL & 50 \\
\hline TOTAL & 150 \\
\hline
\end{tabular}

Table 1 shows that out of these total 150 biopsies, 100 were diagnosed as neoplastic lesions and 50 were diagnosed as non neoplastic lesions. Among the neoplastic lesions, majority cases were of Gliomas (82\%) which was followed by metastatic CNS tumours (13\%). Among the non neoplastic lesions, majority cases were of infectious origin (60\%) followed by cystic lesions (22\%), and reactive gliosis $(12 \%)$.

Table 2: Cases of glial tumors as per who classification

\begin{tabular}{|l|c|c|}
\hline $\begin{array}{c}\text { Histological type of tumor } \\
\text { WHO Classification) }\end{array}$ & $\begin{array}{c}\text { Total } \\
\text { No of cases }\end{array}$ & $\begin{array}{c}\text { Percentage of } \\
\text { Total }\end{array}$ \\
\hline Astrocytic gliomas & 17 & \\
\hline Pilocytic astrocytoma (I) & 6 & \\
\hline Gemistocytic astrocytoma & 18 & \\
\hline Low grade astrocytoma(II) & 3 & \\
\hline Anaplastic astrocytomas (III) & 20 & \\
\hline Glioblastoma Multiforme (IV) & 64 & 78 \\
\hline Total & & \\
\hline Oligodendroglial or mixed glioma & 8 & \\
\hline Oligodendroglioma (II) & 1 & \\
\hline Anaplastic oligodendroglioma (III) & 9 & \\
\hline Total & & \\
\hline Unspecified glioma & 2 & \\
\hline Low grade glioma (II) & 3 & 5 \\
\hline High grade glioma (III) & 5 & \\
\hline Total & 4 & \\
\hline Ependymoma & 82 & 100 \\
\hline Total & \multicolumn{2}{|l}{} \\
\hline
\end{tabular}

Table 2 shows that, out of total 82 cases of gliomas, 64 were of astrocytic Gliomas (78\%) followed by Oligodendroglial or mixed glioma (11\%), Unspecified glioma (6\%) and Ependymoma $(5 \%)$. Most of the Astrocytic gliomas were Pilocytic astrocytoma, Low grade astrocytoma and Glioblastoma Multiforme.

Table 3: Age distribution of cerebral lesions

\begin{tabular}{|l|c|c|c|c|c|c|}
\hline \multirow{2}{*}{ Age } & \multicolumn{3}{|c|}{ Histopathological findings } & \multicolumn{2}{|c|}{ Total } \\
\cline { 2 - 5 } & Neoplastic & \multicolumn{2}{|c|}{ Non-neoplastic } & \multicolumn{2}{c|}{} \\
\hline $0-10$ & 8 & $34.8 \%$ & 15 & $65.2 \%$ & 23 & $15.33 \%$ \\
\hline $11-20$ & 10 & $55.56 \%$ & 8 & $44.44 \%$ & 18 & $12.0 \%$ \\
\hline $21-30$ & 16 & $53.33 \%$ & 14 & $46.67 \%$ & 30 & $20.0 \%$ \\
\hline $31-40$ & 20 & $69.0 \%$ & 9 & $31.0 \%$ & 29 & $19.33 \%$ \\
\hline $41-50$ & 19 & $76.0 \%$ & 6 & $24.0 \%$ & 25 & $16.67 \%$ \\
\hline $51-60$ & 12 & $100.0 \%$ & 0 & $0.0 \%$ & 12 & $8.0 \%$ \\
\hline$>61$ & 12 & $92.3 \%$ & 1 & $7.7 \%$ & 13 & $8.67 \%$ \\
\hline Total & 97 & $64.67 \%$ & 53 & $35.33 \%$ & 150 & $100.0 \%$ \\
\hline
\end{tabular}

Table 3 shows that the age of the patients varied from 1 to $>61$ years. The peak age incidence for patients with neoplastic lesions was the 4 th and 5th decade (20\% for each age group) while that for benign lesions was 1 st and 3 rd decade (15\% for each age group). Where neoplastic lesions were concerned, the youngest patient was 4yrs and oldest was 65yrs of age. 
Table 4: Distribution of glial tumor according to age

\begin{tabular}{|l|c|}
\hline $\begin{array}{c}\text { Histological type of tumor } \\
\text { (WHO Classification) }\end{array}$ & $\begin{array}{c}\text { Mean age } \\
\text { Present study }\end{array}$ \\
\hline Astrocytic gliomas & 17 \\
\hline Pilocytic astrocytoma (I) & 35 \\
\hline Low grade astrocytoma(II) & 40 \\
\hline$-\quad$ Anaplastic astrocytomas (III) & 43 \\
\hline$-\quad$ Glioblastoma Multiforme (IV) & 40 \\
\hline Oligodendroglial or mixed glioma & 40 \\
\hline Low grade oligodendroglioma(II) & \\
\hline Anaplastic oligodendroglioma(III) & \\
\hline
\end{tabular}

From table 4 it is evident that most of the glial tumors are common in the middle age group except for pilocytic astrocytoma which is more common in children.

Table 5: Sex distribution of cerebral lesions

\begin{tabular}{|l|c|c|c|}
\hline \multirow{2}{*}{ Histopathological findings } & \multicolumn{2}{|c|}{ Sex } & \multirow{2}{*}{ Total } \\
\cline { 2 - 3 } & Female & Male & 100 \\
\hline Neoplastic Lesions & 29 & 71 & 50 \\
\hline Non Neoplastic Lesions & 21 & 29 & 150 \\
\hline Total & 50 & 100 & \\
\hline
\end{tabular}

Table 5 shows that the study, which included 150 patients, included 100 male patients and 50 female patients. The male to female ratio was 2.7:1. There was marked male preponderance of neoplastic lesions and slight male preponderance of non neoplastic lesions.

Table 6: Distribution of glial tumor according to sex

\begin{tabular}{|l|c|c|c|}
\hline \multicolumn{1}{|c|}{ Tumors } & $\begin{array}{c}\text { No. of } \\
\text { Male }\end{array}$ & $\begin{array}{c}\text { No. of } \\
\text { Female }\end{array}$ & $\begin{array}{c}\text { Present } \\
\text { series }\end{array}$ \\
\hline Astrocytic gliomas & & & \\
\hline Pilocytic astrocytoma (I) & 13 & 4 & $3.2: 1$ \\
\hline Low grade astrocytoma(II) & 11 & 7 & $1.5: 1$ \\
\hline High grade astrocytoma(III\&IV) & & & \\
\hline$-\quad$ Anaplastic astrocytomas (III) & 1 & 2 & $1: 2$ \\
\hline$-\quad$ Glioblastoma Multiforme (IV) & 16 & 4 & $4: 1$ \\
\hline Oligodendroglial or mixed glioma & & & \\
\hline Oligodendroglioma (II) & 7 & 1 & $7: 1$ \\
\hline Anaplastic oligodendroglioma(III) & 1 & 0 & $1: 0$ \\
\hline Ependymoma & 4 & 2 & $2: 1$ \\
\hline
\end{tabular}

From table 6 it is evident that there is a male predominance of incidence Ratio in all histological subtypes of gliomas.

Out of 100 neoplastic cases which were confirmed by histopathology examination, 92 cases $(92 \%)$ were consistent with radiological diagnosis. And out of 50 non-neoplastic cases which were confirmed by histopathology examination, 44 cases $(88 \%)$ were consistent with radiological diagnosis. So on and average $90 \%$ of all cases were consistent with radiological diagnosis. Only 10\% cases were inconclusive.

\section{Discussion}

CNS is the main host of the different variety of tumors and malignant brain tumors are always aggressive in nature, so patients often succumb to the disease in a less than one year period. The available imaging modalities like Megnatic Resonance Imaging and CAT-scan were proved to be of a particular importance for giving provisional diagnoses but not for definitive or confirmatory diagnosis.

The result of present study, a histopathological study of cerebral lesions are now compared with various studies. It is evident that among the glioma most common is the 
Astrocytoma with $78 \%$, which was followed by the oligodendroglioma with $11 \%$ and then Ependymoma with $6 \%$ in present study which is closely correlate with the study of J.-S. Guillamo et al, Helseth A and Mork SJ et al \& Wolf HK et al. ${ }^{10}$ The authors Bernard RO and Geddes $\mathrm{JF}^{[12]}$ studied a series of 241 gliomas (astrocytomas, oligodendrogliomas, glioblastomas, and subependymal giant-cell astrocytomas). 201 cases $(85 \%)$ were apparently solitary tumors; of the 40 cases with multiple tumor foci, $23(9.5 \%)$ were true multicentric gliomas. ${ }^{11}$ The authors Di Rocco C, Ceddia A, Lannelli A et al ${ }^{[12]}$ report on 51 infants with intracranial tumours treated in an eleven-year period. Males (28 cases) were slightly more frequent. Astrocytomas (17 cases), was most common tumor followed by medulloblastomas (12 cases) and then ependymal tumours (5 cases) were different histologic types. ${ }^{12}$

The mean age of the patients in present study and of study of Kleihues $\mathrm{P}$ et $\mathrm{al},{ }^{13}$ for pilocytic astrocytomas patient age has been shown to be a prognostic factor of major significance in several studies of both oligodendrocytic and astrocytic tumors. This has been suggested to be due to the occurrence of more malignant gliomas at older age. The mean ages for the different gliomas in present studies are closely correlate with the study of Kleihues $\mathrm{P}$ et al. ${ }^{13}$ The age specific incidence for glioblastoma increases with age, whereas the incidence of astrocytoma and oligodendroglioma peaks at middle age. In present study, there is also preponderance of male patients. Male to female ratio was $2.7: 1$.

\section{Summary and Conclusion}

1. Out of these total 150 cerebral biopsies, 100 $(67 \%)$ were diagnosed as neoplastic lesions and $50(33 \%)$ were diagnosed as non neoplastic lesions.

2. Among the neoplastic lesions, most common were Gliomas. Among the gliomas, most common is the Astrocytoma (78\%) followed by the oligodendroglioma $(11 \%)$ and Ependymoma $(6 \%)$ in decreasing order in present study.

3. Overall there is a male predominance $(2.7: 1)$ in the patient with Glial tumors.

4. Pilocytic Astrocytoma is the dominant lesion in the pediatric age group. Low grade astrocytomas comprise of $28 \%$ and high grade gliomas including Glioblastoma multiforme are $32 \%$ of all astrocytomas.

5. Out of 50 non neoplastic cerebral lesions, 30 $(60 \%)$ were of infectious origin. Out of these
30 infectious cerebral lesions, 6 (20\%) were of Tuberculosis and $13(43 \%)$ were of Abscess formations. Incidence of Hydatid cyst is around $18 \%$ amongst cysts and incidence of Reactive gliosis is $12 \%$ amongst Non Neoplastic disease.

6. $90 \%$ of the radiological diagnosis were consistent with the histopathological diagnosis. Only $10 \%$ cases were inconclusive.

\section{References}

1. Guillamo JS, Doz F, Delattre JY. Brain stem gliomas. Curr Opin Neurol 2001;14:711-5.

2. Fuller GN, Burger PC. Central nervous system. In Mills SE (ed.): Histopathology for pathologists, ed. 3. Philadelphia, 2007, Lippincott Williams \& Wilkins, pp. 273-319.

3. Van Meir EG, Handjipanayis CG, Norden AD, Shu HK, Wen PY, Olson JJ. Exciting new advances in neuro oncology: the avenue to a cure for malignant glioma. CA Cancer J Clin 2010;60:166-93.

4. Paul Kleihues, Figen Soylemezoglu, Barbara Schauble, Bernd W. Scheithauer, Peter C. Burger. Histopathology, Classification and Grading of gliomas. GLIA 1995;15:211-21.

5. Louis DN, Ohagi H, Weistler OD, Cavenne WK (eds): WHO classification of tumours of the central nervous system. Lyon, 2007. IARC, pp. 25-49.

6. Fiqarella-Branger D, Colin C, Coulibaly B, Quilichini B, Maues De Paula A, Fernander C et al. Histologic and molecular classification of gliomas. Rev Neurol 2008;164(6-7):505-15.

7. Tohma Y, Gratas C, Biernat W, Peraud A, Fukuda M, Yonekawa Y etal. PTEN (MMAC1) mutations are frequent in primary glioblastomas (de novo) but not in secondary glioblastomas. J Neuropathol Exp Neurol 1998;57(7):684-9.

8. Marc K, Rosenblum. Central nervous system. Rosai and Ackerman's Surgical Pathology, Volume 2, ed. 10. Juan Rosai, Elseveor, pp.2339.

9. Bailey P, Cushing H: A classification of the tumors of glioma group on a histogenetic basis with a correlated study of prognosis. Philadelphia: J.B.Lippincott, 1926.

10. Helseth A, Mork S. Neoplasm of central nervous system in Norway III, epidemiological characteristics of intracranial gliomas according to histology. APMIS 1989;97:547-55.

11. Bernard RO and Geddes JF. The incidence of multifocal cerebral gliomas. A histologic study of large hemisphere sections. Cancer 1987;60(7):1519-31.

12. Di Rocco C, Ceddia A, Lannelli A. Intracranial tumours in the first year of life. A report on 51 cases. Acta Neurochir (wien) 1993;123:14-24.

13. Kleihues P, Burger PC, Collins VP, New Comb EW, Ohgaki H, Cavenee WE et al. Glioblastoma in pathology and genetics of tumours of central nervous system. (Kleihues P, Cavenee WK eds. 2000). IARC Press, Lyon, pp. 29-39. 